Rev. Elet. em Gestão, Educação e Tecnologia Ambiental (e-ISSN: 2236-1170)

\title{
RESÍDUOS DE CURTUMES: ESTUDO DAS TENDÊNCIAS DE PESQUISA
}

\author{
Marcos Vinicius Godecke ${ }^{1}$, Marco Antonio Siqueira Rodrigues ${ }^{2}$, Roberto Harb Naime ${ }^{3}$ \\ ${ }^{1}$ Universidade FEEVALE RS: mgodecke@yahoo.com.br \\ ${ }^{2}$ Universidade FEEVALE: marcor@feevale.br \\ ${ }^{3}$ Universidade FEEVALE: rnaime@feevale.br
}

\section{RESUMO}

Tomando os resíduos de curtumes como objeto de pesquisa, este estudo revisou 41 publicações Science Direct do período de jan/2010 a jun/2011, procurando identificar as tendências das investigações científicas. Foram identificadas quatro vertentes de estudos: toxicidade e mutageneidade (5 publicações), tecnologias de tratamento (20 publicações), valorização econômica (11 publicações) e ecologia, ecoeficiência e gestão (5 publicações). 0 artigo apresenta uma resenha de cada uma dessas publicações, com informações sobre objetivos e principais resultados. A análise das publicações mostrou tratar-se de campo profícuo para novas investigações em diversos ramos científicos relacionados tanto às áreas técnicas como de gestão, além da sua combinação, em escopos interdisciplinares. Novas pesquisas fazem-se necessárias diante do predominante quadro de depleção ambiental, baixa ecoeficiência dos processos industriais e incipiente aproveitamento econômico dos resíduos.

Palavras-Chave: curtumes, resíduos sólidos industriais, efluentes industriais.

\section{ABSTRACT}

Taking waste from tanneries as a research subject, this study identified the trends of these investigations through the review of recent publications. Have been identified four factors: toxicity, treatment technologies, economic value and ecological efficiency. The analysis of publications showed that it is a fruitful field for further research in various scientific fields related to technical and management areas, besides of their combination in interdisciplinary scopes. New studies are necessary before the predominant framework of environmental depletion, low ecoefficiency of industrial processes and incipient economic use of waste.

Keywords: tanneries, industrial solid waste, industrial effluents

\section{INTRODUÇÃO}

O setor coureiro tem participação relevante na economia de diversos países, com as indústrias curtidoras processando anualmente aproximadamente 5,5 bilhões de metros quadrados de couro em negócios na ordem de US\$ 70 bilhões (ABER et al, 2010). Somente nos países da União Europeia funcionavam cerca de 3000 curtumes em 1998 (ZUPANCIC; JEMEC, 2010). O Brasil, líder mundial na exportação de couro, processa anualmente cerca de 42 milhões de couros 
Rev. Elet. em Gestão, Educação e Tecnologia Ambiental (e-ISSN: 2236-1170)

(MARTINES et al., 2010). Essa produção representa aproximadamente $1 \%$ do produto interno bruto (PIB) brasileiro, e emprega cerca de 50 mil trabalhadores. O estado do Rio Grande do Sul concentra o maior número destas instalações, cerca de 200 , com $60 \%$ delas concentradas na região do Vale do Rio dos Sinos (FIGUEIREDO et al, 2010).

O processo de curtimento do couro requer diversos processos mecânicos e químicos de tratamento que, em condições de baixa eficiência, resultam em grande quantidade de efluentes 30 a 35 litros por quilograma de material cru processado - com altas concentrações de matéria orgânica e inúmeros produtos químicos tóxicos, como o Cromo e Sulfato, que podem resultar em irritações na pele, olhos, e trato respiratório, além de cânceres, problemas neurológicos e mutagênicos (RODRIGUES et al, 2008). O processo gera grande volume de resíduos sólidos: na União Europeia são geradas anualmente cerca de 400 a 900 mil toneladas de lamas (por peso úmido), além de 170 mil toneladas de resíduos de couro curtido (ZUPANCIC; JEMEC, 2010).

A relevância econômica da indústria curtidora, conjugada com seu potencial poluidor, vem intensificando nas últimas décadas a realização de pesquisas acadêmicas, que resultaram em maior conhecimento do processo industrial, e na evolução das tecnologias utilizadas para tratamento e racionalização do processo produtivo. Longe de esgotar o assunto, a pesquisa relacionada aos resíduos dos curtumes continua profícua e relevante, pois não só as tecnologias estão em desenvolvimento, como a depleção ambiental decorrente dos processos continua significativa, e muito precisa ser feito na direção da ecoeficiência.

Esse cenário levou à formulação do problema de pesquisa: a situação atual e tendências dos estudos sobre a gestão desses resíduos. A metodologia adotada foi a revisão de 41 publicações recentes sobre o tema ${ }^{1}$. Os artigos foram sintetizados de modo a evidenciar o objetivo de pesquisa, a metodologia adotada, e os principais resultados encontrados. E organizados segundo três diretrizes: afinidade de conteúdo, sequência lógica das etapas do processo de curtimento, e a amplitude de escopo: da particular para a geral. As publicações resultaram classificadas em quatro vertentes de pesquisa: (i) estudos preocupados com os danos à saúde humana, pela toxicidade e mutageneidade dos resíduos; (ii) pesquisas voltadas à redução do impacto ambiental, via melhorias e inovações nas tecnologias de tratamento dos resíduos; (iii) pesquisas interessadas em gerar aproveitamento econômico dos resíduos; e (iv) estudos visando melhorias na gestão, ecoeficiência, e sustentabilidade dos resíduos desse processo industrial.

Além desta introdução e das considerações finais, o texto é formado por tópico de introdução aos inúmeros processos industrais de tratamento do couro, seguido de outros quatro, que agrupam os trabalhos das vertentes de pesquisa.

\section{O PROCESSO INDUSTRIAL E SEUS RESÍDUOS}

Pode-se dividir as operações de processamento industrial do couro, a partir do couro cru (raw hide), em três estágios. As operações iniciais são chamadas beamhouse, compostas por: soaking, a primeira etapa do processo de curtimento, que consiste em promover a limpeza e hidratação do couro; liming, onde são adicionados cal e sulfetos, que elevam o pH e removem quimicamente os pelos; fleshing, que consiste em remover o tecido adiposo sob a pele, e o corte de partes indesejáveis do couro; e splitting, processo de corte horizontal que o padroniza o couro em altura.

Após as operações beamhouse estão as operações tanning, compostas por processos

A amostra compreendeu publicações Science Direct de 2010 até 19 de junho de 2011, incluídos os trabalhos em impressão. 
Rev. Elet. em Gestão, Educação e Tecnologia Ambiental (e-ISSN: 2236-1170)

como: deliming - retirada da cal utilizada no processo liming; bating - remoção de proteínas pelo uso de enzimas; pickling - redução de pH pela utilização de ácidos; tanning - adição de sais de cromo trivalente (Cromo III); e basification - elevação de pH. Ao final deste estágio obtém-se uma commodity, o wet blue.

Novas operações "trabalham" o wet blue, para dar-lhe as características finais desejadas: shaving é um processo de raspagem para o ajuste do couro à espessura desejada; as operações de retanning, dyeing e greasing determinarão as propriedades relativas à cor, maciez, brilho, etc.

A Figura 1 relaciona as etapas do processo até a obtenção do wet blue, com os principais produtos utilizados no processo, e os respectivos resíduos sólidos e efluentes gerados.

Figura 1. Etapas, insumos e resíduos do wet blue.

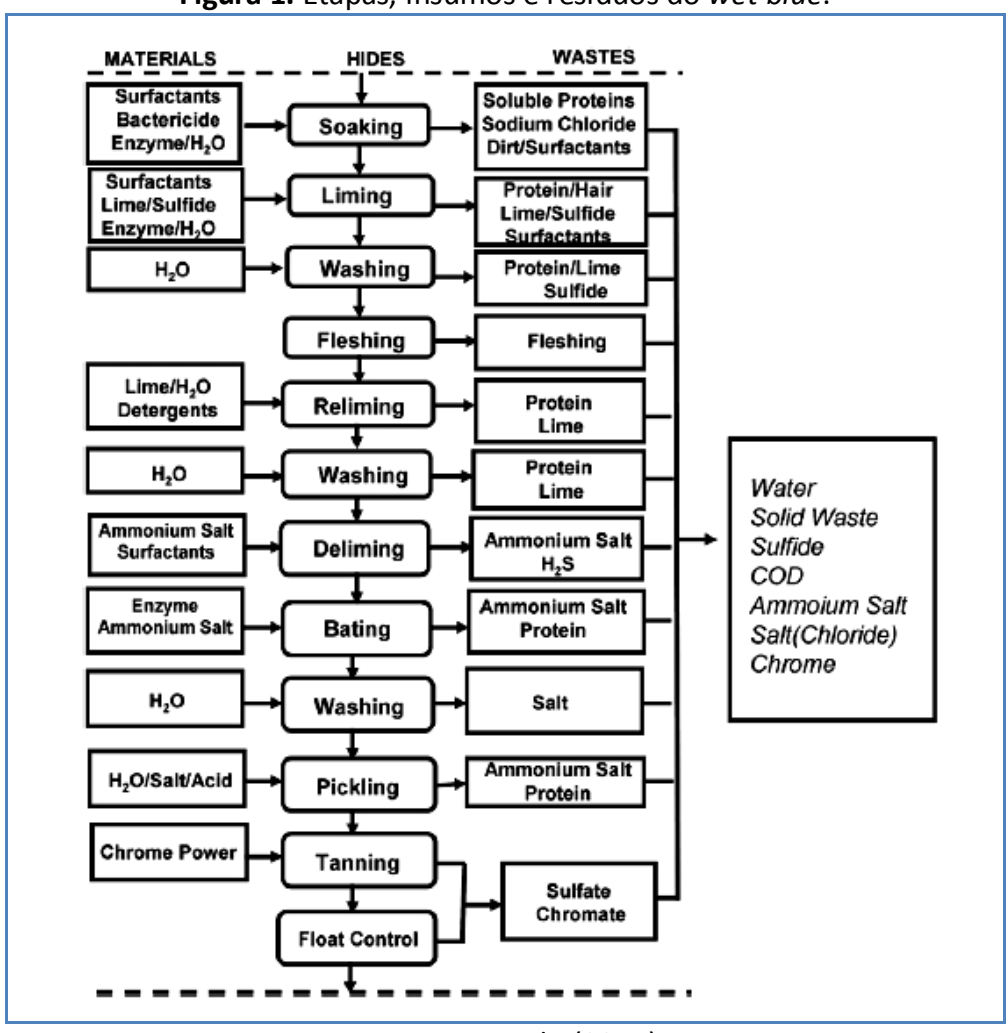

Fonte: Hu et al., (2011)

Uma tonelada de raw hides demanda em torno de 300 a $400 \mathrm{~kg}$ de cloreto de sódio para sua preservação. A segunda maior quantidade de resíduos é constituida pela cal e sulfetos não absorvidos pelas peles. Em terceiro lugar, os pelos, peles, carnes e tecidos adiposos retirados no processo elevam sobremaneira as demandas química e bioquímica de oxigênio (DQO e DBO) dos efluentes. Também, as aminas produzidas nas etapas liming, deliming, bating e retanning provocam o desenvolvimento de um sistema anaeróbio tóxico para muitos microorganismos biodegradantes. Estima-se que os processos de beneficiamento de uma tonelada de couro cru gerem até $350 \mathrm{~kg}$ de carnes e gorduras, $225 \mathrm{~kg}$ de aparas do processo shaving, $150 \mathrm{~kg}$ de retalhos, e $2 \mathrm{~kg}$ de pó de polimento. Além disso o cromo hexavalente (cromo IV), originado pela oxidação do cromo III, tem comprovadas propriedades cancerígenas, mutagênicas e alergênicas (HU et al., 2011).

As publicações relativas à toxicidade e mutageneidade dos resíduos de curtumes são apresentadas no próximo tópico. 
Rev. Elet. em Gestão, Educação e Tecnologia Ambiental (e-ISSN: 2236-1170)

\section{ESTUDOS VOLTADOS AOS DANOS À SAÚDE HUMANA}

A amostra das publicações apresentou cinco artigos que tiveram como escopo aspectos relacionados à toxicidade e mutageneidade dos efluentes de curtumes.

Como os efluentes de curtumes são misturas complexas de poluentes tóxicos, que demandam uma bateria de testes de ecotoxicidade para avaliar o seu potencial de impacto ambiental, e a real eficácia de tratamentos alternativos, Tigini et al. (2011) produziram quatro simulações de efluentes comuns em indústrias têxteis e curtumes: banho ácido para lã, banho ácido para couro, e banhos direto e reativo para algodão. Organismos de diferentes níveis tróficos foram expostos a cada um desses efluentes, visando testar seus níveis de sensibilidade toxicológica. Encontraram elevada toxicidade nos quatro efluentes, porém não encontraram mutagêneidade. Dos organismos testados, a alga Pseudokirchneriella subcapitata apresentou a maior sensibilidade. Os modelos matemáticos utilizados apontaram a interação entre sais como elemento sinérgico para a toxicidade do efluente resultante de banhos reativos utilizados no beneficiamento do algodão.

Lemos et al. (2011) investigaram o potencial mutagênico de amostras das águas superficiais dos rios Cadeia e Feitoria (RS, Brasil), colhidas em áreas influenciadas por efluentes de curtumes. Foram coletadas seis amostras bimestrais de três locais (dois no rio Feitoria - FEI001 e FEI004 e um no rio Cadeia - CAD001), no período de junho de 2001 a março de 2002. Como metodologia analítica foi adotada a cytokinesis-block micronucleus assay (CBMN) usando linfócitos humanos e células $V 79^{2}$. Encontraram indução de micronucleos nos linfócitos em $83 \%$ das amostras dos sites FEI001 e CAD001, e em 33\% das amostras de FEI004. Apenas uma amostra colhida do site FEI004 mostrou resposta positiva de indução em células V79. Os linfócitos mostraram maior sensibilidade às substancias tóxicas, revelando-se excelentes biomarcadores de genotoxidade ambiental. $O$ estudo identificou a presença de substâncias que induzem quebras ou perdas cromossômicas nos locais analisados, corroborando estudos sobre substâncias químicas, toxicidade crônica, estresse oxidativo e mutagenicidade.

Alam et al. (2010) realizaram análise cromatográfica de gás/espectrometria de massa gas chromatography/mass spectroscopy (GC/MS) - de amostras de efluentes de curtumes coletados em estação de tratamento de Kanpur (India), usados durante anos para fertilização de solos agriculturáveis, visando avaliar seu potencial mutagênico e genotóxico. A análise revelou a presença de compostos orgânicos, incluindo di-iso-octyl-ftalato, fenil N-metilcarbamatos, dibutilftalato, bis(2-methoxyethyl)ftalato, e alcanos superiores. Extratos de efluentes de curtume foram preparados com resinas XAD-4/8, diclorometano, clorofórmio e hexano, com o potencial mutagênico verificado pelo teste Ames utilizando Salmonella typhimurium, e o potencial de genotoxidade determinado com a utilização de Escherichia coli K-12. Os resultados obtidos sugeriram a presença de componentes mutagênicos e genotóxicos nos efluentes, suscitando cautela para uso agrícola.

Monteiro Neto et al. (2010) avaliaram a incidência de aberrações cromossômicas em linfócitos periféricos de trabalhadores expostos cronicamente a riscos químicos em um curtume de Franca (Brasil). O grupo de expostos foi formado por dez trabalhadores do sexo masculino, com tempo de empresa variando entre 5 meses e 14 anos. O grupo de controle foi formado por dez homens sem história de exposição a substâncias genotóxicas. A análise de metafases mostrou maior incidência de aberrações cromossomicas no grupo de expostos fumantes $(0,110)$, seguido pelos fumantes não expostos $(0,105)$. Os expostos não fumantes tiveram indice de 0,038 e os não

\footnotetext{
${ }^{2}$ As células V79 são provenientes de fibroblastos do pulmão de Hamster Chinês.
} 
Rev. Elet. em Gestão, Educação e Tecnologia Ambiental (e-ISSN: 2236-1170)

expostos, não fumantes, de 0,023 . Os resultados mostraram um significativo efeito mutagênico do tabagismo, e a exposição laboral crônica de trabalhadores de curtumes a produtos como tintas, corantes e ácidos, um fator de risco relevante para o desenvolvimento de doenças associadas a danos genéticos.

Por fim, Siqueira et al. (2011) investigaram os efeitos de poluentes presentes nos efluentes de curtumes sobre o sistema nervoso central de camundongos, utilizando modelos de depressão e ansiedade desses animais. No estudo foram comparados os efeitos dessas exposições em dois tipos de efluentes de curtumes: tratamento convencional fisico-químico e biológico; e processo avançado com foto-eletro-oxidação (radiação ultravioleta e célula eletroquímica). Os animais foram divididos em cinco grupos: tratamento convencional a 0,1 e 1\%, tratamento avançado a 0,1 e $1 \%$, e grupo de controle. A ansiedade comportamental foi medida pelo teste de labirinto elevado em cruz, e o comportamento depressivo por teste de natação forçada. Nos animais expostos aos efluentes com tratamento convencional encontraram comportamento ansiolítico, mas não depressivo, enquanto que os efluentes tratados pelo processo avançado não geraram sinais de ansiedade ou depressão.

Pela gama de poluentes de elevada toxicidade que carregam, os efluentes de curtumes apresentam potencial para muitos estudos. Os casos apresentados evidenciam a riqueza de alternativas de pesquisa, tanto do ponto de vista da obtenção das amostras - compostos sintéticos, coletas em estações de tratamento, efluentes submetidos a tratamentos alternativos previamente à experimentação, coletas em corpos receptores, etc. - como pela possibilidade do uso de bioindicadores vivos ou células de diferentes origens, inclusive retiradas dos próprios indivíduos expostos à substâncias de comprovada toxicidade, como o cromo IV.

Evidências de toxicidade e mutageneidade reforçam a necessidade dos resíduos sólidos e efluentes dos curtumes receberem tratamentos capazes de reduzir os impactos do seu lançamento no meio ambiente. Esses tratamentos foram o tema de diversas publicações recentes, apresentadas no próximo tópico.

\section{PESQUISAS RELACIONADAS AO TRATAMENTO DOS RESÍDUOS DE CURTUMES}

O alto potencial poluidor dos efluentes de curtumes tem motivado pesquisas que resultaram, nas últimas décadas, em evolução nas tecnologias de tratamento. A contenção da grande carga orgânica, associada a uma variedade de metais pesados tóxicos - cromo, arsênio, cádmio, cobalto, chumbo, níquel, selênio, etc. - inclui inúmeros tipos de tratamentos físicos, químicos, biológicos e suas combinações. Entre eles estão a coagulação, floculação, adsorção, troca iônica, processos eletroquímicos, oxidativos, por radiação, bio e fitorremediação. Este tópico dedica-se a expor publicações recentes cujo principal objetivo foram testes de desempenho de tecnologias ou microorganismos no tratamento desses resíduos.

\subsection{Coagulação}

Situada entre os principais processos convencionais de tratamento físico-químico dos efluentes de curtumes, a coagulação foi objeto das pesquisas de Ayoub et al. (2011) e Aber et al. (2010). 
Rev. Elet. em Gestão, Educação e Tecnologia Ambiental (e-ISSN: 2236-1170)

Ayoub et al. (2011) testaram diferentes doses de bittern ${ }^{3}$, coagulante de baixo custo obtido a partir da evaporação solar da água do mar, como alternativa aos tradicionais sulfato de alumínio e cloreto de ferro no tratamento de efluentes de curtumes, após submeterem o efluente a um processo físico de triagem de tamanho e elevação do $\mathrm{pH}$ com o uso de cal (óxido de cálcio). A seguir, o efluente clarificado passou por uma coluna de adsorção em carbono ativado. Os resultados indicaram elevada remoção de sólidos em suspensão (TSS) (97\%), cor aparente e turbidez (99\%), fósforo total (87\%), e cromo (99,7\%). Obtiveram boas remoções de DQO (71\%) e DBO (57\%). Porém o efluente tratado apresentou elevadas concentrações de sólidos dissolvidos (TDS) (30\%) e alta condutividade (36\%). A remoção de arsênico ficou na faixa de $56 \%$. A comparação do processo de coagulação utilizando bittern, sulfato de alumínio, e cloreto férrico, indicou que os três coagulantes operam igualmente bem quando aplicados em seu valor de $\mathrm{pH}$ ideal.

A busca pelo estabelecimento das condições ideais para a coagulação desses efluentes levaram Aber et al. (2010) a utilizar o método de Taguchi para realizar diversos testes. Experimentaram tipos e doses de coagulantes e coagulantes auxiliares, em diferentes condições de $\mathrm{pH}$, avaliando a eficiência do processo de coagulação - floculação, sobre a DQO, concentração de cromo, TDS, turbidez, e estes em seu conjunto. Encontraram o tipo de coagulante como determinante para a DQO, o pH para a remoção do cromo, o tipo do coagulante auxiliar para a remoção da TDS, e a dose do coagulante auxiliar na remoção de turbidez. As condições ótimas para a remoção de $\mathrm{DQO}$ foram obtidas com $800 \mathrm{ppm}$ de cloreto de ferro III $\left(\mathrm{FeCl}_{3}\right)$ como coagulante, 600 ppm de carbonato de sódio $\left(\mathrm{Na}_{2} \mathrm{CO}_{3}\right)$ como auxíliar de coagulante e pH 7,5. Para a remoção do cromo: $1600 \mathrm{ppm}$ de $\mathrm{FeCl}_{3}$ como coagulante, $100 \mathrm{ppm}$ de cal como coagulante auxiliar e pH 7,5. Para a remoção da TDS: 1600 ppm FeCl 300 ppm de $\mathrm{Na}_{2} \mathrm{SiO}_{3}$ como coagulante auxiliar e pH 9. Para a turbidez: 800 ppm de PAC (cloreto de polyaluminum) como coagulante, 600 ppm $\mathrm{Na}_{2} \mathrm{CO}_{3}$ como coagulante auxiliar, e pH 7,5. As condições ótimas encontradas para a remoção de DQO foram selecionadas como as melhores condições para os casos onde o objetivo do tratamento é a remoção simultânea de todos os parâmetros estudados. Para este caso obtiveram os seguintes resultados: $82,6 \%$ de remoção da DQO, $81 \%$ do cloro, $36 \%$ da TDS, e $85,9 \%$ da turbidez.

Observa-se que mesmo processos tradicionais de tratamento, como a coagulação, permitem novos trabalhos científicos, seja pela exploração de novos coagulantes, que possam resultar em vantagens econômicas ou ambientais, ou mesmo pela discussão sobre o reflexo da variação de concentrações no comportamento de coagulantes clássicos, diante das diversas propriedades fisico-químicas dos efluentes.

\subsection{Adsorção}

Três artigos da amostra valeram-se da capacidade de adsorção de metais e substâncias tóxicas pela biomassa vegetal, dois com a adsorção aplicada aos efluentes e um às lamas do processo. Vinodhini e Das (2010) experimentaram a adsorção de cromo VI de efluentes, utilizando serragem de Neem (Azadirachta indica) como alternativa ao carvão ativado comercial, encontrando conveniências tanto do ponto de vista da eficiência do processo, como vantagens de ordem financeira, pelo baixo custo da biomassa. O experimento ocorreu em leito fixo para um fluxo de efluente em coluna. Os parâmetros foram a profundidade do leito $(5-15 \mathrm{~cm})$ e vazão $(5-15$

\footnotetext{
${ }^{3}$ O coagulante bittern, rico em magnésio, foi obtido a partir da evaporação solar da água do mar Mediterrâneo em Beirut, a partir de um volume

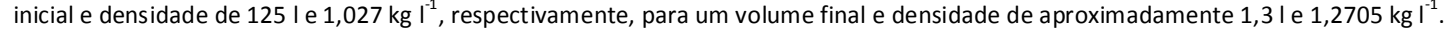


$\left.\mathrm{ml} \mathrm{min}^{-1}\right)$. A capacidade de adsorção encontrada foi de $33 \mathrm{mg} \mathrm{g}^{-1}$. Solução de hidróxido de sódio foi utilizada para a regeneração do adsorvente. Em três ciclos de biossorção, cerca de 3,75 litros de efluente de curtume foram tratados para alcançar o cromo $\mathrm{VI}$ padrão de $0,1 \mathrm{mg} \mathrm{L^{-1 }}$ estabelecido pela indiana Central Pollution Control Board (CPCB).

Por sua vez, Anandkumar e Mandal (2011) mediram a capacidade de adsorção do cromo VI e do corante rodamina B (RB) pelas cascas de cajueiro utilizadas por curtume indiano no curtimento vegetal do couro. Após lavagem, secagem, moagem e peneiramento, a capacidade de adsorção desta biomassa foi testada por ativação térmica $\left(500^{\circ} \mathrm{C}\right)$; ativação química, por $\mathrm{HCl}$; e ativação térmica mais química, nas condições citadas. Esta última resultou em adsorção significativamente mais elevada, variável em função do $\mathrm{pH}$ e temperatura. Os melhores resultados foram obtidos a 50ㄷ: $217 \mathrm{mg} \mathrm{g}^{-1}$ de cromo VI e $250 \mathrm{mg} \mathrm{g}^{-1}$ de RB.

Kilic et al. (2011a) buscaram soluções de remediação econômica e ambiental para os sedimentos do processo de curtimento do couro, testando a capacidade de adsorção do cromo pela casca da Quillaja bark saponin, que possui propriedades biossurfactantes, e compararam os resultados com a utilização do oxidante peróxido de hidrogênio $\left(\mathrm{H}_{2} \mathrm{O}_{2}\right)$. Amostras de lodo de curtume foram tratadas em escala de laboratório com saponina na faixa 2-3 de pH. Foram estudados os efeitos de vários fatores como tempo, concentração de saponina, $\mathrm{pH}$ e temperatura na extração de cromo. O tratamento permitiu a extração de $24 \%$ do cromo após 6 horas de multiplas lavagens a $33 \circ \mathrm{C}$. Por outro lado, o tratamento com $\mathrm{H}_{2} \mathrm{O}_{2}$, que incluiu a oxidação do cromo III para cromo VI e sua extração com solução de ácido sulfúrico ao $\mathrm{pH} 2$, permitiu remover $70 \%$ do cromo em menos de $4 \mathrm{~h}$, à temperatura ambiente $(21 \circ \mathrm{C})$. Os resultados indicaram que a eficiência de extração pela saponina foi fortemente dependente do teor de matéria orgânica da amostra, que afetou a mobilidade do cromo. $\mathrm{O}$ tratamento com $\mathrm{H}_{2} \mathrm{O}_{2}$ mostrou-se conveniente do ponto de vista técnico, pela eficácia e menor duração em temperatura ambiente, e do ponto de vista econômico, por requerer produtos químicos baratos.

Assim como a coagulação, a adsorção é tema profícuo para estudos acadêmicos, pois vasta gama de adsorventes podem ser testados em comparação com o carvão ativado comercial, na busca de vantagens de ordem técnica ou financeira. Sendo que a adsorção pode ser aplicada também ao lodo resultante do processo, conforme demonstrou Kilic et al. (2011a).

\subsection{Processos avançados de tratamento}

A qualidade dos efluentes após tratamentos como a coagulação/floculação e adsorção pode ser insuficiente, dependendo do uso pretendido para o efluente. Quando há necessidade de uma maior qualidade, para reutilização, por exemplo, pode-se utilizar processos por membranas, simples ou com eletrólitos, e processos oxidativos, simples ou avançados. Estes processos, geralmente utilizados após os convencionais e adsorção, podem ser combinados entre si.

Os processos de tratamento que utilizam membranas são classificados em função da dimensão dos poros das membranas e da pressão do efluente sobre a mesma. Vão da microfiltração à osmose inversa (OI), passando pela ultra filtração (UF) e nano filtração (NF). Entre as publicações recentes relacionadas aos processos por membranas estão Roca et al. (2010) utilizando de UF; Religa et al. (2011) e Aleixandre et al. (2011) com a NF; e Prabhavathy e De (2010) com NF e OI.

O estudo de Roca et al. (2010) teve dois objetivos: (i) verificar a influência na qualidade do couro, da reutilização da cal e sulfatos do processo recuperados como permeados em processo de UF, ficando a matéria orgânica retida na membrana, como concentado; e (ii) a comparação 
Rev. Elet. em Gestão, Educação e Tecnologia Ambiental (e-ISSN: 2236-1170)

entre diferentes tipos de limpeza da membrana adotada na pesquisa ${ }^{4}$. Os resultados mostraram que a qualidade final do couro não foi modificada com a reutilização do permeado, e os melhores resultados de limpeza da membrana foram obtidos com o Hipoclorito de Sódio (92\% de recuperação de fluxo) e com a dosagem de ar do lado do permeado.

Religa et al. (2011) testaram num primeiro momento a influência da concentração de íons de cromo III, cloro e sulfato na composição do efluente de curtume durante processo NF. Num segundo momento, a influência da pressão transmembrânica para o fluxo de permeado, retenção de cromo III e cloro, bem como a concentração de cromo III. Encontraram uma faixa ideal de pressão entre 14 e 16 bar, concluindo que o processo apresentou alto e estável fluxo de permeado, com sucesso na concentração de cromo III. Verificaram que o envelhecimento do cromo reduziu pouco a eficiência do processo.

Aleixandre et al. (2011) utilizaram a membrana Desal5 DL, da GE Osmosnics, para filtrar sulfatos das águas residuárias de processos liming, visando o reaproveitamento do produto, com a consequente redução da sua carga no meio ambiente. Concluiram que a simples combinação de $50 \%$ des águas residuais desse processo com $50 \%$ de água doce permite a obtenção de couro com uma qualidade aceitável, reduzindo em $10 \%$ a adição do produto. A NF permitiu a retençao de $97 \%$ dos sulfatos para o reuso. Calcularam que a aplicação combinada das duas medidas, mistura e $\mathrm{NF}$, permite uma redução de $14,82 \mathrm{~kg}$ de $\mathrm{SO}_{4} \mathrm{t}^{-1}$ de couro cru.

Prabhavathy e De (2010) trataram efluentes de curtumes ricos em materiais orgânicos com a seguinte sequência: sedimentação, decantação de sólidos em suspensão, coagulação em dois estágios, NF e OI. Os processos de coagulação, que utilizaram sulfato de ferro e cal permitiram redução da DQO de 13688 para $4921 \mathrm{mg} \mathrm{L}^{-1}$. A NF, utilizando pressões entre 828 e $1242 \mathrm{kPa}$ em três regimes de turbulência, resultou em redução da DQO para valores entre $1300 \mathrm{e}$ $2700 \mathrm{mg} \mathrm{L}^{-1}$. Os mesmos regimes de turbulência foram utilizados na Ol, sob pressões entre $1313 \mathrm{e}$ $1724 \mathrm{kPa}$, para atingir o limite de DQO permitido na Índia, de $250 \mathrm{mg} \mathrm{L}^{-1}$. Os resultados ficaram entre 117 e $174 \mathrm{mg} \mathrm{L}^{-1}$. Compararam os resultados experimentais relativos a coeficientes de transporte da OI com os calculados utilizando modelos teóricos e encontraram aderência entre os resultados.

A oxidação eletroquímica (OEQ) pode ser uma alternativa à coagulação química e aos processos com membranas. É alternativa também para processos biológicos, que apresentam pouco resultado na remoção da DQO em efluentes com alta concentração de sais inorgânicos. Na amostra, três artigos testaram a oxidação eletroquímica de efluentes de curtumes: Benhadji et al. (2011), Sundarapandiyan et al. (2010) e Costa et al. (2010).

Benhadji et al. (2011) utilizaram eletrocoagulação e eletroflotação para a remoção simultânea de poluentes orgânicos e inorgânicos em curtume da Argélia. Utilizaram alumínio e aço no cátodo e alumínio no ânodo, testando diferentes tempos de aplicação e tensões elétricas. Encontraram condições ótimas em uma corrente de $75 \mathrm{~A} \mathrm{~m}^{-2}$ durante 45 minutos, obtendo reduções superiores a $90 \%$ de DBO5, DQO, turbidez, cromo, ferro e nitrato. Constataram a importância do material catódico para o tratamento, e o fato da concentração de nitritos ter ficado acima do limite aceitável. Encontraram quantidades relevantes de metais pesados, como cromo, carbono orgânico e sulfetos nos sedimentos do processo, que demandariam tratamento em caso de reutilização.

Sundarapandiyan et al. (2010) testaram a utilização de grafite em ambos os eletrodos para redução da DQO e do Nitrogênio Kjeldahl Total (NKT) de efluentes do processo soaking, de

\footnotetext{
${ }^{4}$ Os autores adotaram a membrana IRIS 3065, da ORELIS, com $30 \mathrm{~cm}^{2}$ de área ativa.
} 
Rev. Elet. em Gestão, Educação e Tecnologia Ambiental (e-ISSN: 2236-1170)

alta carga orgânica, salinidade elevada ${ }^{5}$ e alto teor de sólidos suspensos. Os parâmetros observados no tratamento OEQ foram $\mathrm{pH}$, tempo e densidade de corrente, em concentração salina igual ou superior a $30 \mathrm{~g} \mathrm{~L}^{-1}$. Os melhores resultados em termos de DQO e NKT foram obtidos em pH 9, tempo de 2 horas, e corrente de $0,024 \mathrm{~A} \mathrm{~cm}^{-2}$. Fator de maior custo no tratamento, a energia elétrica, resultou em 22,45 kWh para a redução de $1 \mathrm{~kg}$ de TKN e 0,80 kWh para igual redução de DQO. Foram realizados três processos em escala comercial de reuso do efluente, com a recuperação do sal, sem significativa perda de qualidade do couro.

Costa et al. (2010) testaram a utilização de diferentes ânodos DSA (dimensionally stable anodes) para tratamento por OEQ de um efluente artificial, produzido para simular o efluente natural de um processo pickling, com adição de sulfato de sódio $\left(\mathrm{Na}_{2} \mathrm{SO}_{4}\right)$ na concentração 0,10 $\mathrm{mol} \mathrm{L}^{-1}$ e $\mathrm{pH}=2.4^{6}$. Os parâmetros foram o $\mathrm{pH}$ e a densidade de corrente sobre a DQO, fenóis totais, Carbono Orgânico Total (COT), turbidez e absorvência. Entre os ânodos testados, o Si/BDD teve o melhor desempenho. $\mathrm{O}$ ânodo $\mathrm{Ti} / \mathrm{SnO}_{2}-\mathrm{Sb}$ apresentou bons resultados, mas teve desgaste muito rápido: desativação completa em $4 \mathrm{~h}$ de eletrólise com $25 \mathrm{~mA} \mathrm{~cm}{ }^{-2}$. O ânodo Ti/ $\mathrm{SnO}_{2}-\mathrm{Sb}-\mathrm{Ir}$ mostrou-se mais estável do que o anodo $\mathrm{Ti} / \mathrm{SnO}_{2}-\mathrm{Sb}$, mas os autores concluiram não ser adequado para o tratamento eletroquímico, nas condições estudadas. Pequenas variações de $\mathrm{pH}$ não se mostraram significativas para a eletrólise com Si/BDD, sendo que este eletrodo obteve a quase completa mineralização em $4 \mathrm{~h}$ na corrente de $100 \mathrm{~mA} \mathrm{~cm}{ }^{-2}$. Aumentos na intensidade da corrente aceleraram a oxidação do efluente sintético, porém com perda de eficiência em relação a mínima testada $\left(25 \mathrm{~mA} \mathrm{~cm}^{-2}\right)$.

Interessante observar que três dos trabalhos citados - Roca et al. (2010), Aleixandre et al. (2011) e Sundarapandiyan et al. (2010) - além dos objetivos ligados a avaliação de tecnologias (membranas, eletrodos), preocuparam-se também em recuperar as águas e produtos dos processos, todos resultando em avaliações positivas.

Nos tratamentos apresentadas até o momento predominaram soluções de natureza física e química. Mas são múltiplas as oportunidades de pesquisa associando microbiologia e botânica aos resíduos de curtumes, confome demonstram os estudos apresentados no próximo tópico.

\subsection{Biorremediação}

Seis dos artigos estudados referem-se à atuação de microorganismos associada a resíduos de curtumes. Sharma e Adholeya (2011) e Wang et al. (2011) relativos a tratamentos com fungos; Rai et al. (2010) e Pillai et al. (2011) utilizando bactérias. Os demais (Chandra et al., 2011 e Essahale et al., 2010) às espécies bacterianas existentes em ambientes específicos: lamas de curtumes e curso d'água poluído por curtumes, respectivamente.

Apesar da limitação na utilização de microorganismos na indústria curtidora em condições reais, devido às variações nas características fisico-químicas dos diversos tipos e composições dos resíduos nas diferentes fases do processo, mas com vistas a eventual integração dos processos biológicos na remoção e recuperação do cromo de curtumes, visando melhorias de eficiência e sustentabilidade ambiental, Sharna e Adholeya (2011) recuperaram cromo VI e cromo III através do Paecilomyces lilacinus fungi, na presença de açúcar de cana como fonte de carbono. Constataram que o fungo tem ampla gama de tolerância ao $\mathrm{pH}$ e pode reduzir cromo $\mathrm{VI}$ tanto em ambiente ácido $(\mathrm{pH} \mathrm{5,5)} \mathrm{como} \mathrm{alcalino}(\mathrm{pH} \mathrm{8,0)}$. O fungo mostrou capacidade de remover cromo

\footnotetext{
5 Cerca de $15 \%$ a $40 \%(w / w)$ de sal comum é usado em operações de imersão. O processo soaking utiliza 10\% (w / w) (SUNDARAPANDIYAN et al., 2010).

6 Segundo os autores, o $\mathrm{Na}_{2} \mathrm{SO}_{4}$ auxilia, mas não é necessário para uma boa OEQ. Foi adotado para evitar a formação de organoclorados persistentes, que ocorrem na ausência de cloretos.
} 
VI $\left(1,24 \mathrm{mg} \mathrm{L}^{-1}\right)$ e cromo total $\left(7,91 \mathrm{mg} \mathrm{L}^{-1}\right)$ a níveis inferiores aos de deteç̧ão, no prazo de 18 e 36 horas de incubação, respectivamente. E a capacidade de acumular 189,13 mg de cromo por grama de biomassa seca em 600 horas de incubação, a partir de uma concentração inicial de $3731,4 \mathrm{mg} \mathrm{L}^{-}$ ${ }^{1}$ de cromo III. Propuseram novos estudos visando otimizar as condições, para melhoria da eficiência, redução de custos e recuperação do cromo por dessorção da biomassa de fungos.

Wang et al. (2010) introduziram o fungo Rhodotorula mucilaginosa $R 30$ em lodo de curtume para testar a melhoria no processo de biolixiviação. Trata-se de microorganismo heterotrófico e ácido-tolerante que tem se mostrado eficaz para a biodegradação de ácidos orgânicos de baixo peso molecular ou de matéria orgânica dissolvida (MOD) em lamas tóxicas para as bactérias Acidithiobacillus. Verificou-se que a ação do $R$. mucilaginosa $R 30$ foi triplamente benéfica para o processo de biolixiviação: (i) aumentou a concentração de $\mathrm{CO}_{2}$ dissolvido, que é benéfico para o crescimento das Acidithiobacillus; (ii) as substâncias poliméricas extracelulares (SPE) resultantes da incorporação dos microrganismos heterotróficos melhoraram a biolixiviação pela fixação do ion $\mathrm{F}^{+3}$ na forma solúvel SPE-ferro III, reduzindo a perda de $\mathrm{Fe}^{+3}$ por precipitação; além de (iii) "limparem" a MOD de substâncias tóxicas às Acidithiobacillus. Segundo os autores, a contribuição relativa dos três fatores pode ser melhor investigada em estudos futuros, de modo a ampliar o conhecimento sobre o comensalismo existente entre essas espécies.

Rai et al. (2010) utilizaram Enterococcus faecium HAB01 (GenBank \# FJ418568), bactéria presente no ácido láctico, para otimizar a hidrólise de proteínas e a atividade antioxidante nas operações de fermentação do material sólido ${ }^{7}$ obtido com o descarne dos couros, com potencial para aplicação na formulação de alimentos animais. Foram testadas três variáveis independentes: nível de inóculo, nível de glicose, e o tempo de fermentação, usando o método Response Surface Methodology (RSM) $)^{8}$ para obter os graus de hidrólise e acidez (DPPH radical scavenging activity) como variáveis de resposta. As condições otimizadas de hidrólise foram encontradas com 12,5\% ( $v$ / w) de inóculo, 17,5\% (w / w) de glicose e $96 \mathrm{~h}$ de fermentação a $37 \pm 1$ 으. A porção líquida do resíduo apresentou potencial para ingrediente de alto valor alimentar. Concluiram que a utilização do E. Faecium HAB01 pode oferecer maior utilidade para o resíduo de cortumes, a baixos custos e impactos ambientais. Além de melhor hidrólise enzimática e propriedades antioxidantes, o produto resulta rico em aminoácidos. Os autores sugerem experimentos com animais para avaliar a segurança e qualidade do fermentado.

Pillai et al. (2011) testaram o poder enzimático da protease EC $3.4^{9}$ produzida pelo Bacillus subtilis P13 - obtido nas termas Vajreshwari, próximas à Mumbai (Índia) - nos processos de pré-curtimento: soaking, dehairing (liming) e fibre opening (reliming). O objetivo dos autores foi contribuir para a redução dos entraves à utilização de proteases na remoção dos pelos de couros, buscando a diminuição nos custos para a concentração das enzimas, e obtenção de cepas mais tolerantes a gradientes de $\mathrm{pH}$ e temperatura dos processos industriais. A otimização foi obtida em duas etapas: a identificação dos constituintes significativos do meio de cultura, seguida por cálculos estatísticos da concentração ideal de cada um desses constituintes. A aplicação da metodologia resultou em aumento de 3,2 vezes na produção da protease extracelular pelo bacilo, com redução do tempo de cultura à metade. A capacidade da protease para executar as etapas de pré-curtimento foram confirmadas por ensaios em curtumes, e os melhores resultados obtidos com a protease de $\sim 31 \mathrm{kDa}$.

\footnotetext{
Na Índia esses resíduos atingem 150 mil toneladas ao ano (RAl et al., 2010).

8 Giovanni, 1983, apud Rai et al., 2010.

9 Nomenclatura do Committee of the International Union of Biochemistry and Molecular Biology para classificação das reações de catalise de enzimas. As proteases da classe EC 3.4 constituem cerca de $40 \%$ do mercado de enzimas, com aplicações na indústria de detergentes, couros, alimentos e farmacos (PILLAl et al., 2011).
} 
Rev. Elet. em Gestão, Educação e Tecnologia Ambiental (e-ISSN: 2236-1170)

Chandra et al. (2010) utilizaram as metodologias polymerase chain reaction-restriction fragment length polymorphism (PCR-RFLP) e gas chromatography-mass spectrometry (GC-MS) para caracterizar a diversidade de bactérias, poluentes orgânicos e seus metabólitos, em duas lagoas aeradoras de tratamento de efluentes da indústria curtidora. Realizaram coletas em diferentes estações do ano e compararam os efluentes anteriores e posteriores ao tratamento. Os resultados revelaram que as comunidades bacterianas predominantes na lagoa I foram Escherichia sp., Stenotrophomonas sp., Bacillus sp. e Cronobacter sp., enquanto na lagoa II prevaleceram Stenotrophomonas sp. e Burkholderiales. As análises HPLC (high-performance liquid chromatography) e GC-MS revelaram maior concentração de poluentes orgânicos nos efluentes sem tratamento, comparativamente aos efluentes degradados pelas bactérias, sendo que apenas dois poluentes: ácido lático L-(+)- e ácido acético não puderam ser degradados, e outros dois: ácido benzeno e 2-hidroxi-3-metil-butanóico foram produzidos como novos metabólitos durante tratamento bacteriano na lagoa II. Observou-se expressiva degradação e redução da toxicidade ${ }^{10}$ dos efluentes após o tratamento bacteriano, que permitiram a germinação de sementes hidratadas com efluentes oriundos das lagoas I (70\%) e II (90\%).

Essahale et al. (2010) realizaram análise química da água do rio Binlamdoune, localizado na região Medina de Fez (Marrocos), que revelou forte impacto de elementos tóxicos provenientes de curtumes e outras atividades industriais ${ }^{11}$. Para determinar a eficácia da biorremediação estudaram a abundância e diversidade de bactérias das águas do referido rio e de efluentes de curtumes da cidade de Fez. Para tal, aplicaram o método polymerase chain reactiondenaturing gradient gel electrophoresis (PCR-DGGE) na área do $16 \mathrm{~S}$ rDNA. Encontraram uma comunidade de bactérias pertencentes a grupos eubacterianas: Epsilonproteobacteria, Lactobacillales, Bacteroidetes, Clostridia, Gammaproteobacteria, e Alphaproteobacterie. Além de outras pertencentes ao grupo Firmicutes. Também realizaram microscopia eletrônica de varredura (Scanning electron microscopy) de efluentes de curtumes, que revelou riqueza bacteriana nos efluentes do couro tratado de forma moderna, onde a análise EDAX mostrou concentração de cromo $(39,26 \%)$. A mesma análise no couro tratado tradicionalmente revelou a presença de $\mathrm{Na}$ $(51,43 \%), \mathrm{S}(43,23 \%)$, e $\mathrm{Cl}(3,81 \%)$, sem detectar a presença de metais pesados.

Os exemplos apresentados: populações de bactérias versus tipos de efluentes, redução de toxicidade após tratamento bacteriano, aplicação de proteoses na remoção de pelos, otimização da hidrólise de proteínas, melhoria no processo de biolixiviação, e utilização de fungos para a remoção de cromo - demonstraram riqueza de possibilidades de pesquisa aplicada aos resíduos de curtumes no âmbito da microbiologia.

Após os tratamentos elencados, desde coagulação até biorremediação, tem-se a fitorremediação como alternativa para a extração de metais pesados residuais provenientes da disposição final dos resíduos sólidos e efluentes dos curtumes.

\subsection{Fitorremediação}

Dois dos artigos estudados testaram o plantio de espécies vegetais como forma de remediar solos contaminados com efluentes de curtumes. Shukla et al (2011) experimentaram cinco espécies de plantas (Terminalia Arjuna, Prosopis juliflora, Populus alba, Eucalyptus

Na lagoa II, redução de DBO (92\%), DQO (86.87\%), ST, (89.75\%) NT (58.13\%), sulfato (54.58\%), fosfato (70.49\%), e poluentes orgânicos (77.02\%).

${ }^{11}$ Na parte baixa do rio encontraram, entre outros elementos, $\mathrm{P}$ (10154), S (33993), Ca (108749), Cr (0.048), As (e 0.087), em mg L ${ }^{-1}$. 
Rev. Elet. em Gestão, Educação e Tecnologia Ambiental (e-ISSN: 2236-1170)

tereticornis e Dendrocalamus strictus) para fitorremediação em depósitos de lodo de curtumes na Índia. Medições iniciais encontraram as seguintes concentrações de metais tóxicos: $\mathrm{Fe}(1667)>\mathrm{Cr}$ (628) $>\mathrm{Zn}(592)>\mathrm{Pb}(427)>\mathrm{Cu}(354)>\mathrm{Mn}(210)>\mathrm{Cd}(125)>\mathrm{Ni}$ (76), em mg kg-1. As performances de crescimento das plantas foram acompanhadas e após um ano de fitorremediação, o nível de remoção de metais tóxicos do lodo chegou a $\mathrm{Cr}(70,22 \%), \mathrm{Ni}(59,21 \%)$, $\mathrm{Cd}(58,4 \%)$, Fe $(49,75) \%, \mathrm{Mn}(30,95 \%), \mathrm{Zn}(22,80 \%)$, Cu $(20,46 \%)$ e Pb $(14,05 \%)$.

No Paquistão, Bareen e Tahira (2011) colonizaram com doze espécies de plantas uma área considerada infértil devido à contaminação provocada pela indústria do couro. Entre elas, a Suaeda fruticosa, Salvadora oleoides e Calatropis procera apresentaram melhor desempenho na formação de biomassa. A S. fruticosa foi submetida a novas experiências por demonstrar, também, elevada capacidade de fitoextração de metais. Os experimentos em laboratório e em campo ocorreram simultaneamente, utilizando o mesmo tipo de solo. Foram utilizadas diferentes concentrações do quelante sintético ácido etilenodiaminotetracético (EDTA) para testar sua capacidade de melhoria na fitorremediação. Pequenas quantidades de EDTA mostraram-se positivas para a biorremediação, porém quantidades maiores resultaram em perda significativa de biomassa. A maior quantidade de cromo foi bioacumulado pelas folhas de $S$. fruticosa, seguidas pelas raízes e caule.

As publicações apresentadas neste tópico demonstram que os efluentes de curtumes representam um campo multidisciplinar aberto para pesquisas ligadas aos seus tratamentos. Os trabalhos aprsentados no próximo tópico introduzem um enfoque novo: como aproveitar o potencial econômico desses resíduos.

\section{PESQUISAS VOLTADAS AO APROVEITAMENTO ECONÔMICO DOS RESÍDUOS DE CURTUMES}

Se os resíduos de curtumes representam séria ameaça à saúde humana e ao meio ambiente, também trazem alternativas de aproveitamento econômico que vêm estimulando pesquisas relacionadas ao uso industrial, produção de alimentos, emprego na área médica, como fonte alternativa de energia, e como fertilizante agrícola.

\subsection{Aproveitamento econômico como insumo na medicina}

A amostra trouxe caso de aplicação de resíduos beamhouse na área médica, o artigo de Rao e Nair (2011): diante da informação que, na Índia, o processamento de uma tonelada de couro implica na geração de 30 a $40 \mathrm{~m}^{3}$ de efluentes com aproximadamente 0,2 a 0,3\% (em peso úmido) de Glocosaminoglicanos (GAG) ou mucopolissacarídeos, elemento de elevado valor comercial utilizado em drogas anti-hemorrágicas, antitrombóticas e em tecidos artificiais, os autores procuraram desenvolver um processo prático e pouco custoso para a extração do GAG desses efluentes. Testaram diferentes pesos molares do polímero polietilenoglicol (PEG) associado ao ácido poliacrílico (PAA), em diferentes temperaturas, $\mathrm{pH}$, concentrações do polímero entre as fases (tie line length-TLL) e concentrações de $\mathrm{NaCl}$. Utilizaram centrifugação para separar o efluente em duas fases, pelo processo aqueous two-phase system (ATPS). Obtiveram o melhor resultado $(91,5 \%)$ utilizando PEG 4000 , em pH 8,0 e temperatura de 20 으. Utilizaram também o método ATPS em escala semi-comercial, obtendo 5,5g de GAG a partir de $10 \mathrm{~L}$ de efluente, mais $3,2 \mathrm{~kg}$ de PEG 4000 e 2,2 kg de PAA.

O próximo tópico mostra que ao invés do simples aterramento ou incineração, os 
Rev. Elet. em Gestão, Educação e Tecnologia Ambiental (e-ISSN: 2236-1170)

resíduos do processo de curtimento podem biodigeridos em reatores, com o aproveitamento do biogás e do composto orgânico resultantes do processo.

\subsection{Aproveitamento econômico pela produção de biogás}

O desenvolvimento de mercados de energia alternativa, conjugado com o aumento dos custos de tratamento dos efluentes de cortumes, vem tornando a produção de biogás uma opção atraente. Nesse contexto, Zupancic e Jemec (2010) investigaram o tratamento anaeróbio de diferentes tipos de resíduos de curtumes, resultantes das operações de descarne, aparas de pele e lamas de efluentes, através de dois processos: convencional semi-contínuo e anaerobic sequencing batch reactor (ASBR). Os experimentos foram realizados em três partes: (i) ensaios para a determinação do potencial de metano (SMP) ${ }^{12}$ em cada substrato, nas temperaturas de 37으 e 55으, de acordo com a ISO 11734 (1994) e OECD 311 (2006); (ii) procedimentos de "start$u p^{\prime 13}$ e os experimentos de digestão anaeróbia pelo método convencional, em reator com escala de laboratório; (iii) novos experimentos utilizando o processo ASBR, para comparação com o anterior. A 55C acharam uma SMP de 0,617 $\mathrm{m}^{3} \mathrm{~kg}^{-1}$ no efluente, $0,377 \mathrm{~m}^{3} \mathrm{~kg}^{-1}$ nas aparas, e $0,649 \mathrm{~m}^{3} \mathrm{~kg}^{-1}$ para os resíduos das operações de descarne. Cromo e salinidade não apresentaram efeitos adversos, mas uma redução de de 4,4 ㄷ $\mathrm{C}$ na temperatura do reator levou a uma queda de $25 \%$ na produção de biogás, indicando o controle da temperatura como um importante fator de eficiência no processo. Pelo processo ASBR alcançaram a SMP de $0,596 \mathrm{~m}^{3} \mathrm{~kg}^{-1}$, com a remoção de $71,4 \%$ dos sólidos voláteis em suspensão (VSS), no nível de processamento (OLR) ${ }^{14}$ de $3,96 \mathrm{~kg} \mathrm{~m}^{-3}$ $\mathrm{d}^{-1}$.

$\mathrm{Na}$ busca de soluções eficientes e baratas para o tratamento dos efluentes de cortumes, El-Sheikh et al. (2011) testaram dois reatores anaeróbios do tipo upflow anaerobic sludge blanket (UASB), construídos em escala de laboratório (volumes de 94 L) e ligados em série. Experimentaram cinco tempos de retenção hidráulica (HRT): 24, 18,12,8, e 5 h. Concluiram que a HRT de $12 \mathrm{~h}$ seria a ideal para a remoção conjunta da DBO, DQO, STS e sulfato. E HRT de $8 \mathrm{~h}$ como a mínima aceitável para o cumprimento da legislação Egípcia. Com relação à geração de biogás, a melhor eficiência ocorreu com $8 \mathrm{~h}$ de retenção.

Mannucci et al. (2010) realizaram uma revisão da literura sobre processos anaeróbios de tratamento dos efluentes resultantes de processos vegetais de curtimento de couro. Destacaram entre as vantagens do processo a baixa produção de lodo e o reduzido consumo de energia, além da capacidade de redução da DQO, que vai de $60 \%$ a até mais de $95 \%$, dependendo de diversos fatores ${ }^{15}$. Nas desvantagens estão (i) a necessidade de pré-tratamento dos efluentes, de modo a garantir alta eficiência na remoção de matéria orgânica; a (ii) necessidade de implementação de sistemas adequados de remoção de $\mathrm{H}_{2} \mathrm{~S}$; e a (iii) concentração de taninos e outros compostos biorefratários. Constataram que a maioria dos estudos sobre esse processo de tratamento referemse a experimentos em escala-piloto. Avaliaram que a tendência crescente de transferência da industria de curtumes de paises de clima temperado para países de clima tropical aumentam as perspectivas do processo anaeróbio. Encontraram que a maioria dos experimentos estudaram o reator UASB (29 publicaçãoes) e up-flow anaerobic filters (UAF)/down-flow anaerobic filters (DAF)

\footnotetext{
${ }^{12}$ Specific methane productivity (SMP ): em $\mathrm{m}^{3}$ de metano por kg de sólidos voláteis em suspensão - volatile suspended solids (VSS) inseridos no reator.

${ }^{13}$ Os autores levaram 100 dias para adaptar cepas de mesófilos coletados em lodo de estação de tratamento para o experimento.

${ }_{14}^{14}$ Organic loading rate (OLR): $\mathrm{kg}$ de VSS por $\mathrm{m}^{3}$ de digestão ao dia, onde VSS é obtido pela DQO (g $\mathrm{L}^{-1} \mathrm{ou} \mathrm{mg} \mathrm{g}^{-1}$, degradação em \%)

${ }^{15}$ A eficiência do processo depende de fatores como temperatura, carga orgânica, tempo de retenção hidráulica, concentração de sulfatos, material de enchimento (nos filtros anaeróbios), e de substâncias

inibidoras da metanogênese, tais como sulfetos, taninos, cloretos, e amônia (MANNUCCl et al., 2010).
} 
Rev. Elet. em Gestão, Educação e Tecnologia Ambiental (e-ISSN: 2236-1170)

(21 publicações), em pesquisas sobre: a eficiência na remoção da DQO, sulfatos e taninos; controle na concorrência entre as bactérias sulfate reducing bacteria (SRB) e methanogenic bactéria (MB); produção de biogás; e influência de substâncias tóxicas como inibidoras do processo. A revisão da literatura permitiu concluir que a aplicação combinada de processo anaeróbio e aeróbio resulta em maior eficiência na redução da matéria orgânica, comparativamente ao uso isolado dos processos.

\subsection{Aproveitamento econômico como fertilizante agrícola}

Preocupados com a situação atual na India, onde aproximadamente 3000 indústrias de curtumes geram cerca de 150 mil toneladas de resíduos sólidos orgânicos e 1200 a $1300 \mathrm{~m}^{3} \mathrm{~d}^{-1}$ de efluentes líquidos, na sua maioria - 94\% - despejados diretamente no meio ambiente (apenas $5 \%$ são compostados), levaram Vig et al. (2011) a pesquisar a capacidade da minhoca Eisenia fétida em converter o lodo de curtume, misturado com estrume bovino, em fertilizante. Testaram as proporções 0:100 (T0), 10:90 (T10), 25:75 (T25), 50:50 (T50) e 75:25 (T75). Como o lodo sem mistura é letal para a Eisenia f., o mínimo de mortalidade e o maior acúmulo de população ocorreu na mistura T0. Obtiveram resultados satisfatórios, porém decrescentes para maiores proporções de lodo. A medição inicial dos elementos químicos e seu incremento com a compostagem foram de: nitrogênio $(7,3-66,6 \%)$, sódio $(16,90-70,58 \%)$, fósforo $(8,57-44,8 \%)$ e pH $(2,8-13,65 \%)$. Outros elementos apresentaram reduções em relação à situação inicial: potássio $(4,34-28,5 \%)$, carbono orgânico $(7,54-22,35 \%)$ e condutividade elétrica $(32,35$ $53,12 \%)$. A razão $C: N$ diminuiu sensivelmente durante o processo: dos $20,53 \%$ iniciais para $47,36 \%$ nos produtos finais ${ }^{16}$. O aumento de concentração dos metais $\mathrm{Cu}, \mathrm{Mn}$, Fe e $\mathrm{Zn}$ ficou dentro dos limites legais indianos, e a concentração de cromo não foi medida.

Motivados pela constatação que, como maior exportador mundial, o Brasil processa anualmente cerca de 42 milhões de couros, com geração aproximada de $100 \mathrm{~L}$ de efluentes nas diversas fases do processamento de cada unidade, onde cerca de $4,5 \%$ é constituida de material orgânico eficaz na fertilização e neutralização de solos ácidos, ponderada a situação atual brasileira de minimização dos riscos decorrentes do uso do cromo $^{17}$, Nakatani et al. (2011) verificaram os impactos na estrutura e atividade da comunidade bacteriana de solos no município de Rolândia (PR, Brasil), pela aplicação de lodo de curtume (baixo teor de cromo) em sete aplicações, nos anos de 2006 e 2007. Foram aplicadas diferentes concentrações de N, entre 0 e $1200 \mathrm{~kg} \mathrm{ha}^{-1}$, com a comunidade bacteriana analisada por PCR/DGGE. Análise principal response curve (PRC) mostrou estímulo da atividade bacteriana após a primeira aplicação, que perdurou por 300 dias. Na segunda o estímulo foi de menor duração (260 dias). Esta análise também mostrou que as atividades enzimáticas relacionadas com o ciclo do $\mathrm{N}$ (asparaginase e urease) foram as mais estimuladas. A análise redundancy analysis (RDA) mostrou que a influência do lodo sobre a atividade microbiana está relacionada principalmente aos aumentos de $\mathrm{N}$ inorgânico e ao $\mathrm{pH}$ do solo. Os resultados mostraram que as mudanças na estrutura da comunidade bacteriana nos solos estudados estavam diretamente relacionadas às mudanças de sua atividade biológica.

Experimento de escopo semelhante - contribuição do lodo de curtume para o aumento e atividade da biomassa bacteriana - foi desenvolvido por Santos et al. (2011) em escala de

\footnotetext{
16 A sensível redução na relação C:N foi atribuída pelos autores à perda de carbono como dióxido de carbono, através da respiração microbiana, simultaneamente à adição de nitrogênio pelas minhocas ao excretar mucos nitrogenados.

17 Além da redução na quantidade de cromo por melhorias de processos, as indústrias brasileiras vem empregando o sulfato de $\mathrm{cromo}\left[\mathrm{Cr}_{2}\left(\mathrm{SO}_{4}\right)^{3}\right.$ ], que representa uma forma menos tóxica, que geralmente é complexada por matéria orgânica, tanto das lamas como dos solos. O Cr (III) é a forma predominante no lodo e permanece nesta forma no solo, especialmente em pH acima de 5,5 (NAKATANI et al., 2010).
} 
Rev. Elet. em Gestão, Educação e Tecnologia Ambiental (e-ISSN: 2236-1170)

laboratório, utilizando solos arenosos e argilosos coletados no estado brasileiro do Piauí. Os solos foram alterados por taxas de 7.5, 15, 30 e $60 \mathrm{mg} \mathrm{ha}^{-1}$, equivalentes a 0.3, 0.6, 1.2 e $2.4 \mathrm{~g}$ por $100 \mathrm{~g}$ de solo, respectivamente. E incubados a $28 \stackrel{\circ}{\circ}$, com verificações aos 15,30 e 60 dias de incubação. A respiração do solo foi acompanhada por medições diárias de $\mathrm{CO}_{2}$; a atividade microbiana foi estimada pelo método proposto por Vance et al. (1987, apud Santos et al., 2011), onde o carbono orgânico foi medido por digestão de dicromato; a hidrólise de diacetato de fluoresceína (fluorescein diacetate hydrolysis - FDA) ocorreu de acordo com o método proposto por Schnurer e Rosswall (1982, apud Santos et al., 2011); e a desidrogenase determinada pelo método descrito por Casida et al. (1964, apud Santos et al., 2011). Os resultados foram obtidos pela média de quatro repetições, e comparados por análise de variância (ANOVA). Foram obtidos resultados positivos com baixa taxa, onde a aplicação de $7,5 \mathrm{mg} \mathrm{ha}^{-1}$ aumentou significativamente a atividade e biomassa microbiana, sem efeitos sobre as enzimas do solo. Por outro lado, maiores concentrações não afetaram negativamente os microrganismos do solo e suas atividades.

Com base no mesmo experimento descrito em Nakatani et al. (2011), relativo à aplicação de lodo de curtume em solos de Rolândia, Martines et al., (2010) mediram a perda de nitrogênio pela volatilização da amônia, visto não encontrarem informações sobre esse processo em solos tropicais. Para tanto, utilizaram modelo baseado na equação proposta por Michaelis-Menten. Constataram uma volatilização mais intensa nos primeiros 30 dias de cada aplicação, levando a uma perda total média de $17,5 \%$ do total de $\mathrm{N}$ aplicado, além de $35 \%$ do $\left(\mathrm{NH}_{4}{ }^{+}-\mathrm{N}\right)$ presente no lodo. Concluiram que essa perda deve ser levada em consideração quando a lama de curtume não for imediatamente incorporada ao solo.

Da amostra, três estudos aplicaram compostos com lamas de curtumes para a fertilização de vegetais. A Tabela 1 apresenta as misturas, vegetais utilizados nas pesquisas e os resultados obtidos pelos experimentos.

Onze artigos da amostra tiveram como objetivo principal a geração de receitas a partir de resíduos, fato que demonstra a preocupação dos estudos acadêmicos com a busca de soluções sustentáveis para problemas ambientais e sanitários. Nos casos estudados, ganhos financeiros estimulam o cumprimento das legislações ambientais pelas indústrias curtidoras, resultando em benefícios que vão desde a redução nos volumes de resíduos aterrados ou incinerados, até reduções na extração de reservas naturais e consumo de energia elétrica, pela substituição de fertilizantes industrializados.

Tabela 1. Uso de resíduos de curtumes como fertilizante

\begin{tabular}{|c|c|c|c|}
\hline \multirow[t]{2}{*}{$\begin{array}{l}\text { Silva et al. } \\
\text { (2010) }\end{array}$} & $\begin{array}{l}\text { Capsicum } \\
\text { ornamental }\end{array}$ & $\begin{array}{l}\text { 1) lodo de curtume + palha de cana } \\
\text { de açúcar + esterco bovino: 01:03:01 } \\
\text { (v: v: v) } \\
\text { 2) lodo de curtume + palha de } \\
\text { carnaúba + esterco bovino: 01:03:01 } \\
\text { (v: v: v) }\end{array}$ & \multirow[t]{2}{*}{$\begin{array}{l}\text { Ambas as misturas resultaram em } \\
\text { incremento no no de folhas e frutos, } \\
\text { comprimento do caule, e conteúdo de } \\
\text { clorofila. O conteúdo de clorofila foi } \\
\text { maior nas plantas da mistura } 1 \text { em } \\
\text { comparação com a mistura } 2 \text {. }\end{array}$} \\
\hline & & $\begin{array}{l}\text { Misturas com o solo (\% v:v): } 0 \% \text {, } \\
25 \%, 50 \%, 75 \% \text { e } 100 \%\end{array}$ & \\
\hline \multirow[t]{3}{*}{$\begin{array}{l}\text { Gupta et } \\
\text { al. (2010) }\end{array}$} & $\begin{array}{l}\text { Brassica } \\
\text { campestris }\end{array}$ & $\begin{array}{l}\text { A) lodo de curtume + cinzas de } \\
\text { carvão: 04:01 (v: v) }\end{array}$ & \multirow{3}{*}{$\begin{array}{l}\text { A mistura } A(\geq 10 \%) \text { foi considerada } \\
\text { adequada devido ao melhor rendimento } \\
\text { e menor acúmulo de metais na semente } \\
\text { de } B \text {. Campestris. }\end{array}$} \\
\hline & & $\begin{array}{l}\text { B) lodo de curtume + cinzas de } \\
\text { carvão: 04:02(v: v) }\end{array}$ & \\
\hline & & $\begin{array}{l}\text { Misturas com o solo (\% v:v): } 0 \%, 5 \% \text {, } \\
10 \%, 15 \%, 20 \%, 100 \% \text {, }\end{array}$ & \\
\hline
\end{tabular}


Rev. Elet. em Gestão, Educação e Tecnologia Ambiental (e-ISSN: 2236-1170)

\begin{tabular}{|c|c|c|c|}
\hline $\begin{array}{c}\text { Ravindran, } \\
\text { Sekaran } \\
\text { (2010) }\end{array}$ & $\begin{array}{c}\text { Lycopersicon } \\
\text { esculentum, } \\
\text { Vigna radiata, } \\
\text { Lagenaria } \\
\text { siceraria } \\
\text { Cucumis sativus } \\
\text { L. }\end{array}$ & $\begin{array}{l}\text { Animal fleshing (ANFL) hidrolisado } \\
\text { com Selenomonas ruminantium } \\
\text { HM000123 ( } 8 \mathrm{~kg} \text { ) + esterco bovino ( } 6 \\
\mathrm{~kg} \text { ) + folhas secas ( } 6 \mathrm{~kg} \text { ), misturados }\end{array}$ & $\begin{array}{l}\text { A estabilidade do produto final foi } \\
\text { obtida após } 49 \text { dias de compostagem, } \\
\text { com redução significativa de pH, COT, } \\
\text { C:N.Além da remoção de patogênicos e } \\
\text { aumento do NKT. A germinação das } \\
\text { sementes ficou entre } 84 \% \text { e } 94 \% \text {. }\end{array}$ \\
\hline
\end{tabular}

Fonte: Elaboração dos autores

Outras publicações recentes, apresentadas a seguir, lançam sobre a atividade curtidura um olhar mais amplo, com escopos relacionados à gestão, ecoeficiência e sustentabilidade desta atividade industrial.

\section{PESQUISAS RELATIVAS À GESTÃO, ECOEFICIÊNCIA E SUSTENTABILIDADE}

Cinco artigos da amostra apresentaram caráter diferenciado, relacionando os resíduos de curtumes a aspectos ligados à ecologia, gestão e sustentabilidade, demonstrando a tendência dos estudos acadêmicos de avançarem da visão disciplinar para a interdisciplinar, onde o objeto de pesquisa é visto de forma holística, sistêmica e integrada.

Em estudo no âmbito da ecologia, Szalinska et al. (2010) colheram amostras da água e sedimentos de locais do rio Dunajec (Polônia) fortemente impactados pelo lançamento de efluentes de curtumes, para o estudo do ciclo anual do cromo, e a ocorrência de oxidação do cromo III para cromo VI. Para tanto foram coletadas amostras mensais, durante um ano, da água e sedimento, visando identificar a presença de cromo (III e VI) e manganês ${ }^{18}$ dissolvidos, em suspensão e nos sedimentos do rio. O estudo demonstrou que a incidência, transporte e destino do cromo no sistema aquático foram restritos, tanto em termos temporais quanto espaciais. Em termos temporais, foram encontradas maiores concentrações nos meses de maior atividade industrial (novembro a março). Em termos espaciais, o padrão de distribuição mostrou-se, em grande parte, definido pela localização e características das fontes poluidoras (curtumes). Após a descarga, a distribuição e mobilidade do cromo foram determinadas pelas condições do ciclo hidrológico. As maiores concentrações do metal foram encontradas nos sedimentos (até 1,22 mg $\mathrm{g}^{-1}$ ). A existência de um reservatório à jusante dos pontos de poluição limitaram a extensão geográfica da poluição pelo cromo. A correlação entre as proporções de cromo III/cromo VI e as concentrações de $\mathrm{Mn}$, em sedimentos à jusante do reservatório, sugerem a possibilidade de oxidação do cromo III para cromo VI em condições naturais.

Além da obtenção de receitas pela comercialização dos resíduos do processo industrial, as indústrias curtidoras podem minimizar custos pelo reuso da água e reaproveitamento dos produtos químicos utilizados no processo, como o sal, cal e cromo. Em vista disso, Gutterres et al. (2010) buscaram a minimização do consumo de água nos processos beamhouse, pelo seu reuso em algumas etapas do processo. Realizaram testes em escala piloto e industrial. Em escala de laboratório realizaram dois testes: reutilização dos efluentes da etapa pre-deliming washing na etapa pre-deliming, e os esfluentes da etapa first bating washing na deliming/bating. Em escala industrial, utilizaram os efluentes first e second bating washing nas etapas deliming/bating e predeliming, conforme mostra a Figura 2. Verificaram que a qualidade do couro wet blue nos sistemas

\footnotetext{
${ }^{18}$ A oxidação do cromo é teoricamente possível na presença óxidos de Mn (IV) (SZALINSKA et al., 2010).
} 
Rev. Elet. em Gestão, Educação e Tecnologia Ambiental (e-ISSN: 2236-1170)

com reuso de água manteve-se dentro das especificações de qualidade da indústria. Também desenvolveram o lay-out de interligação dos efluentes nos processos citados, e modelagem matemática visando otimizar o suprimento de água, sem e com reuso, com as diferentes necessidades dos processos. Em escala industrial, o reuso proporcionou uma redução de $27 \%$ no consumo da água requrida nos processos beamhouse.

A partir dos conceitos de circular economy (CE) e industrial ecology (IE), que buscam a ecoeficiência dos processos industriais, Hu et al. (2011) estudaram as operações de curtimento do couro (beamhouse e tanning), buscando aplicar os princípios dos quatro "R" - redução, reutilização, reciclagem e recuperação - sobre os efluentes, produtos químicos, água, e energia. $\mathrm{Na}$ aplicação do modelo ao reuso da água, obtiveram as possibilidades apresentadas na Figura 3. Trouxeram o caso de indústria coureira do norte da China que investiu no reuso da água dos processos pickling e chroming, obtendo recuperação de $25 \%$ no sal e $30,8 \%$ no cromo utilizados nos processos, resultando em economia anual de $16 \mathrm{mil}$ e $471 \mathrm{mil} \mathrm{kg}$ destes produtos, respectivamente, com ganhos financeiros na ordem de 3,5 milhões de renminbis (aproximadamente US\$ 543 mil).

Kiliç et al. (2011b) utilizaram a o método análise do ciclo de vida (ACV) para comparar um tratamento de lodo de curtume com recuperação do cromo, com o tratamento convencional, sem este aproveitamento. Foram consideradas três opções de melhoria: a redução no consumo de água, o reaproveitamento dos produtos recuperados, e a digestão anaeróbia do lodo previamente à recuperação do cromo. A simulação foi realizada utilizando o software GaBi 4 (PE Internacional Stuttgart, Alemanha), e a estimativa dos impactos ambientais através dos fatores desenvolvidos pelo Centrum voor Milieukunde Leiden (CML). Os resultados mostraram que o processo proposto de recuperação do cromo é ambientalmente melhor do que a deposição em aterro convencional, em todas as categorias de impacto avaliadas, se a quantidade de cromo recuperado for superior a $43 \mathrm{~kg}$ por tonelada de lodo - concentração de cerca de 100.000 ppm - quantidade 20 vezes maior do que a considerada no estudo, mas não incomum na literatura, segundo informaram os autores.

No âmbito da gestão empresarial, Pophali et al. (2011) conjugaram a técnica para a tomada de decisões complexas - analytic hierarchy process (AHP) - com a técnica de seleção da alternativa ótima grey relational analysis (GRA), para a seleção de plantas de tratamento de efluentes de curtumes. Para tanto, os processos de tratamento de sete curtumes no sul da Índia foram hierarquizados sob fatores econômicos (capital para investimento e operação, área necessária para o tratamento), técnicos (parâmetros de tratamento) e administrativos (facilidade de operação). O estudo, ainda em andamento, mostrou que a AHP e a GRA são ferramentas poderosas para subsidiar decisões envolvendo alternativas tecnológicas de processos de tratamento de efluentes de curtumes. 
Rev. Elet. em Gestão, Educação e Tecnologia Ambiental (e-ISSN: 2236-1170)

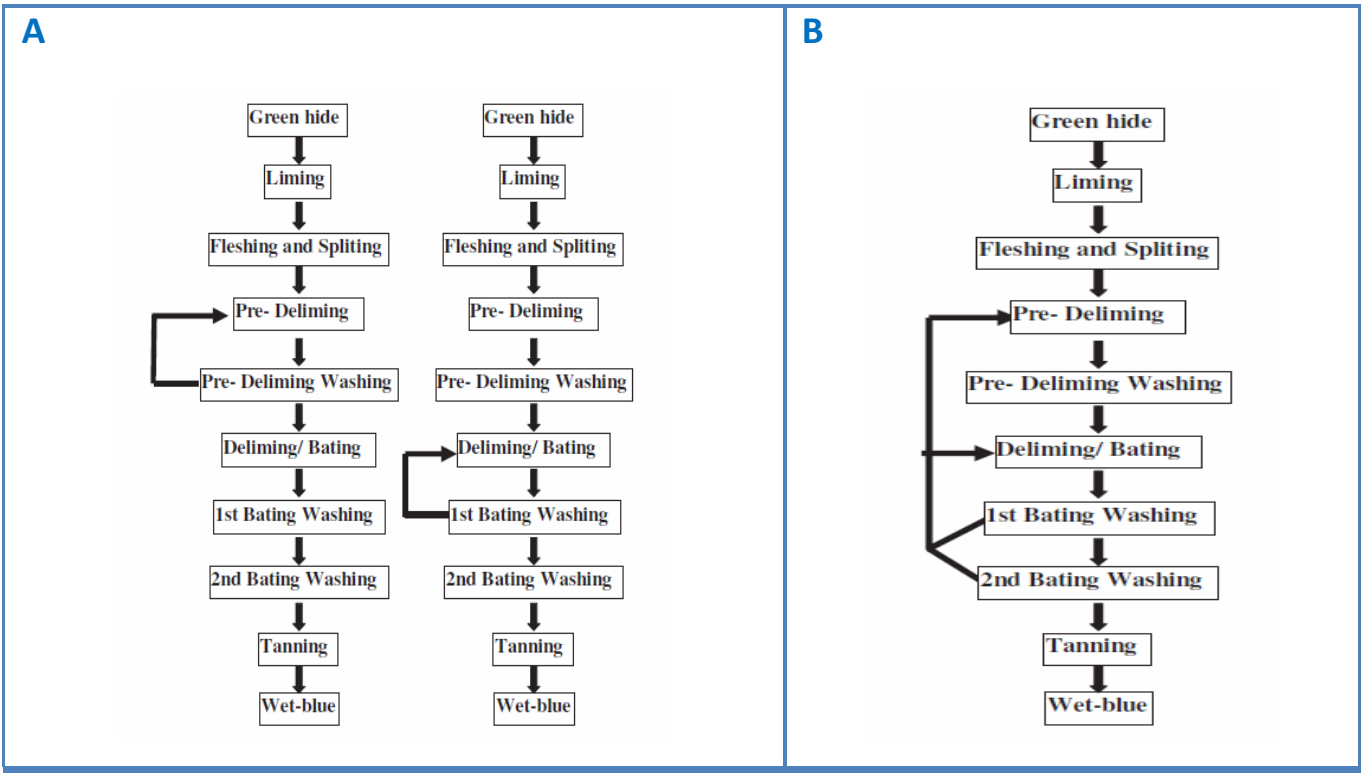

Figura 2. Testes de reuso da água de processos beamhouse em escala piloto (A) e industrial (B)

Fonte: Gutterres et al. (2010)

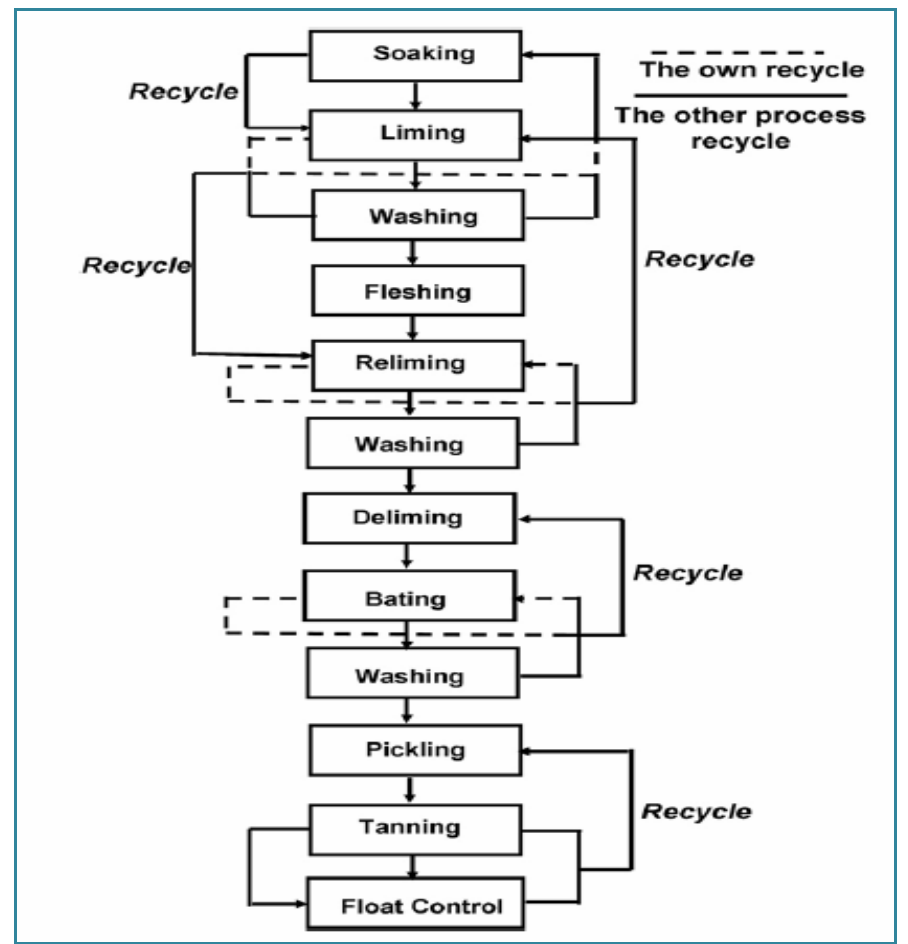

Figura 3. Esquema de aplicação dos 4 " $\mathrm{R}$ " nos processos beamhouse e tanning Fonte: Hu et al. (2011)

Aspectos relativos ao curtimento do couro, como a importância econômica dessa atividade industrial; a complexidade dos processos: diversas etapas, insumos e resíduos; a diversidade de efluentes e resíduos sólidos gerados; a relevância do espectro de malefícios 
decorrentes do descarte no meio ambiente; e as possibilidades de aproveitamento econômico desses resíduos, o tornam tema de interesse acadêmico para áreas de pesquisa nas quais é tema tradicional, como para diversas outras, incluindo abordagens interdisciplinares, conforme demonstram os artigos deste tópico.

\section{CONSIDERAÇÕES FINAIS}

Tomando os resíduos da indústria curtidora como objeto de estudo, este artigo analisou publicações recentes para conhecer as tendências desta pesquisa. $O$ estudo das afinidades permitiu agrupá-las em quatro vertentes: estudos de toxicologia e mutageneidade, processos de tratamento dos resíduos, valorização econômica e busca da ecoeficiência, gestão e sustentabilidade. A participação de cada grupamento nas publicações analisadas é apresentada no Gráfico 1.

Gráfico 1. Participação das vertentes de estudo nas publicações Science Direct sobre resíduos de curtumes, 2010 a jun/2011

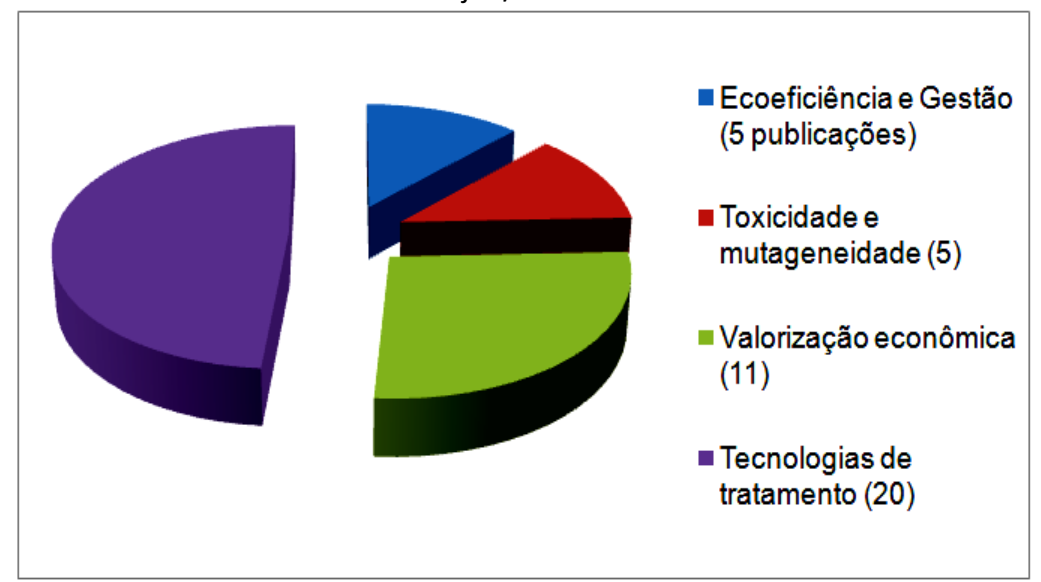

Fonte: Elaboração dos autores

Os estudos de toxicidade constituem um campo com crescente interesse de pesquisa que tem nos efluentes de curtumes um vasto campo de pesquisa. Os cinco artigos estudados testaram amostras obtidas por diversos meios: compostos sintéticos, coletas em estações de tratamento, efluentes submetidos a tratamentos avançados, e coletas em corpos receptores, utilizando bioindicadores vivos ou células de diferentes origens, inclusive humanas.

Os processos alternativos de tratamento constituem a maior área de estudo, num espectro que abrange tanto os resíduos sólidos quanto os efluentes dos curtumes, em tratamentos que podem combinar diversos recursos de natureza física, química e biológica. A amostra trouxe 20 casos de aplicações ligadas à coagulação, adsorção, processos avançados com a utilização de membranas, eletrólise, oxidação, bio e fitorremediação.

Cerca de $25 \%$ dos trabalhos se voltaram ao potencial econômico dos resíduos, para aproveitamento na área médica, energética e agrícola. Essas alternativas, combinadas com a redução de custos pelo reuso da água e dos produtos químicos dos processos, além da racionalização no uso de energia, estiveram presentes em diversos outros artigos, demonstrando forte tendência dos artigos acadêmicos procurarem inovações que aliem aspectos técnicos a financeiros, aumentando a ecoeficiência dos processos industriais e estimulando os 
Rev. Elet. em Gestão, Educação e Tecnologia Ambiental (e-ISSN: 2236-1170)

empreendedores a alcançar os níveis legais de qualidade dos resíduos, não só por coerção legal, mas pelo interesse na geração de receitas, combinada com redução de despesas. Para que essas tendências resultem em efetiva transformação social, são de grande valia as pesquisas que estudam os processos industriais de forma integrada, experimentando novos lay-outs, amparadas por modelagem matemática, colocando em prática conceitos como 4 " $R$ ", análise de ciclo de vida, técnicas de gestão e tomada de decisão.

A análise das publicações relativas aos resíduos produzidos pela indústria curtidora demonstra que muito se avançou no estudo do tema, mas evidencia inúmeras oportunidades para novas investigações, que têm o desafio de reverter o atual quadro de depleção ambiental, resultado da baixa ecoeficiência dos processos industriais e incipiente aproveitamento econômico dos resíduos.

\section{REFERÊNCIAS}

ABER, S.; SALARI D.; PARSA, M.R. Employing the Taguchi method to obtain the optimum conditions of coagulation-flocculation process in tannery wastewater treatment. Chemical Engineering Journal 162 (2010) 127-134.

ALAM, M.Z. et al. Mutagenicity and genotoxicity of tannery effluents used for irrigation at Kanpur, India. Ecotoxicology and Environmental Safety 73 (2010) 1620 -1628.

ALEIXANDRE, M.V.G.; ROCA, J.A.M.; PIÁ, A.B. Reducing sulfates concentration in the tannery effluent by applying pollution prevention techniques and nanofiltration. Journal of Cleaner Production 19 (2011) 91 - 98.

ANANDKUMAR, J.; MANDAL, B. Adsorption of chromium(VI) and Rhodamine B by surface modified tannery waste: Kinetic, mechanistic and thermodynamic studies. Journal of Hazardous Materials 186 (2011) 1088-1096.

AYOUB, G.M.; HAMZEH, A.; SEMERJIAN, L. Post treatment of tannery wastewater using lime/bittern coagulation and activated carbon adsorption. Desalination 273 (2011) 359-365.

BAREEN, F.; TAHIRA S.A. Metal accumulation potential of wild plants in tannery effluent contaminated soil of Kasur, Pakistan: Field trials for toxic metal cleanup using Suaeda fruticosa. Journal of Hazardous Materials 186 (2011) 443-450.

BENHADJI, A.; AHMED, M.T.; MAACHI, R. Electrocoagulation and effect of cathode materials on the removal of pollutants from tannery wastewater of Rouïba. Desalination (2011). Article in Press (20 jun. 2011).

CHANDRA, R. et al. Bacterial diversity, organic pollutants and their metabolites in two aeration lagoons of common effluent treatment plant (CETP) during the degradation and detoxification of tannery wastewater. Bioresource Technology 102 (2011) 2333-2341.

COSTA, C.R. et al. Electrochemical oxidation of synthetic tannery wastewater in chloride-free aqueous media. Journal of Hazardous Materials 180 (2010) 429-435.

EL-SHEIKH, M.A. et al. Biological tannery wastewater treatment using two stage UASB reactors. Desalination (2011). Article in press (20 jun. 2011).

ESSAHALE, A. et al. Bacterial diversity in Fez tanneries and Morocco's Binlamdoune River, using 16S RNA gene based fingerprinting. Journal of Environmental Sciences 2010, 22(12) 1944-1953. 
Rev. Elet. em Gestão, Educação e Tecnologia Ambiental (e-ISSN: 2236-1170)

FIGUEIREDO, J.A.S; PRODANOV, C.C.; DAROIT, D. Impacts of the globalized economy on the environment: the tanning industry in the Vale do Rio dos Sinos. Brazilian Journal of Biology (2010) vol. 70, no. 4 (suppl.), p. 12311243.

GUPTA, A.K. et al. Growth, metal accumulation and yield performance of Brassica campestris L. (cv. Pusa Jaikisan) grown on soil amended with tannery sludge/fly ash mixture. Ecological Engineering 36 (2010) 981-991.

GUTTERRES, M. et al. Water reuse in tannery beamhouse process. Journal of Cleaner Production 18 (2010) 1545 $-1552$.

$\mathrm{HU}$, J. et al. Ecological utilization of leather tannery waste with circular economy model Journal of Cleaner Production 19 (2011) $221-228$.

KILIÇ, E. et al. Chromium recovery from tannery sludge with saponin and oxidative remediation. Journal of Hazardous Materials 185 (2011) 456-462. a

Environmental optimization of chromium recovery from tannery sludge using a life cycle assessment approach. Journal of Hazardous Materials (2011). Accepted Manuscript in 20 jun. 2011. b

LEMOS, A.O.; OLIVEIRA, N.C.D.; LEMOS, C.T. In vitro micronuclei tests to evaluate the genotoxicity of surface water under the influence of tanneries. Toxicology in Vitro 25 (2011) 761-766.

MANNUCCI, A. Anaerobic treatment of vegetable tannery wastewaters: A review. Desalination 264 (2010) 1-8.

MARTINES, A.M. et al. Ammonia volatilization in soil treated with tannery sludge.

Bioresource Technology 101 (2010) 4690-4696.

MONTEIRO NETO, M.A.B. et al. Frequency of chromosomal aberrations in peripheral lymphocytes of tannery workers in Brazil. Environmental Toxicology and Pharmacology 29 (2010) 3-6.

NAKATANI, A.S. et al. Changes in the genetic structure of Bacteria and microbial activity in an agricultural soil amended with tannery sludge. Soil Biology \& Biochemistry 43 (2011) $106-114$.

PILLAI, P.; MANDGE, S.; ARCHANA, G. Statistical optimization of production and tannery applications of a keratinolytic serine protease from Bacillus subtilis P13. Process Biochemistry 46 (2011) 1110-1117.

POPHALI, G.R.; CHELANI, A.B.; DHODAPKAR, R.S. Optimal selection of full scale tannery effluent treatment alternative using integrated AHP and GRA approach. Expert Systems with Applications 38 (2011) 10889-10895.

PRABHAVATHY, C.; DE, S. Treatment of fatliquoring effluent from a tannery using membrane separation process: Experimental and modeling. Journal of Hazardous Materials 176 (2010) 434-443.

RAI, A.K. et al. Utilization of tannery fleshings: Optimization of conditions for fermenting delimed tannery fleshings using Enterococcus faecium HAB01 by response surface methodology. Bioresource Technology 101 (2010) 1885-1891.

RAO , J.R.; NAIR, B.U. Novel approach towards recovery of glycosaminoglycans from tannery wastewater. Bioresource Technology 102 (2011) 872-878.

RAVINDRAN, B.; SEKARAN, G. Bacterial composting of animal fleshing generated from tannery industries. Waste Management 30 (2010) 2622-2630.

RELIGA, P.; KOWALIK, A.; GIERYCZ, P. Application of nanofiltration for chromium concentration in the tannery 
Rev. Elet. em Gestão, Educação e Tecnologia Ambiental (e-ISSN: 2236-1170)

wastewater. Journal of Hazardous Materials 186 (2011) 288-292.

ROCA, J.A.M. et al. Purification of tannery effluents by ultrafiltration in view of permeate reuse. Separation and Purification Technology 70 (2010) 296-301.

RODRIGUES, M.A.S. Application of photoelectrochemicaleelectrodialysis treatment for the recovery and reuse of water from tannery effluents. Journal of Cleaner Production 16 (2008) $605-611$.

SANTOS, J.A. et al. Tannery sludge compost amendment rates on soil microbial biomass of two different soils. European Journal of Soil Biology 47 (2011) $146-151$.

SHARMA, S.; ADHOLEYA, A. Detoxification and accumulation of chromium from tannery effluent and spent chrome effluent by Paecilomyces lilacinus fungi. International Biodeterioration \& Biodegradation 65 (2011) 309 $-317$.

SHUKLA, O.P. et al. Growth responses and metal accumulation capabilities of woody plants during the phytoremediation of tannery sludge. Waste Management 31 (2011) 115-123.

SILVA, J.D.C. et al. Effect of different tannery sludge compost amendment rates on growth, biomass accumulation and yield responses of Capsicum plants. Waste Management 30 (2010) 1976-1980.

SIQUEIRA, I. R. et al. Anxiety-like behaviour in mice exposed to tannery wastewater: The effect of photoelectrooxidation treatment. Neurotoxicology and Teratology (2011). Article in press (20 jun. 2011).

SUNDARAPANDIYAN, $S$ et al. Electrochemical oxidation and reuse of tannery saline wastewater. Journal of Hazardous Materials 180 (2010) 197-203.

SZALINSKA, E. et al. Seasonal transport pattern of chromium(III and VI) in a stream receiving wastewater from tanneries. Applied Geochemistry 25 (2010) 116-122.

TIGINI, V. et al. Evaluation of toxicity, genotoxicity and environmental risk of simulated textile and tannery wastewaters with a battery of biotests. Ecotoxicology and Environmental Safety 74 (2011) 866-873.

VIG, A.P. et al. Vermicomposting of tannery sludge mixed with cattle dung into valuable manure using earthworm Eisenia fetida (Savigny). Bioresource Technology (2011). Article in press (20 jun.2011).

VINODHINI, V.; DAS, N. Packed bed column studies on $\mathrm{Cr}$ (VI) removal from tannery wastewater by neem sawdust. Desalination 264 (2010) 9-14.

WANG, S.; ZHENG, G.; ZHOU, L. Heterotrophic microorganism Rhodotorula mucilaginosa R30 improves tannery sludge bioleaching through elevating dissolved $\mathrm{CO} 2$ and extracellular polymeric substances levels in bioleach solution as well as scavenging toxic DOM to Acidithiobacillus species. Water Research 44 ( 2010 ) $5423-5431$.

ZUPANCIC, G.D.; JEMEC, A. Anaerobic digestion of tannery waste: Semi-continuous and anaerobic sequencing batch reactor processes. Bioresource Technology 101 (2010) 26-33. 